\title{
UM ESTUDO DA REINCIDÊNCIA NA CIDADE DE CAMPINAS-SP
}

Fernanda Carolina de Araujo Ifanger ${ }^{7}$

Nathália Bortoletto Gravina ${ }^{2}$

\section{Palavras-Chave}

criminologia / direito penal / controle social / reincidência / Campinas

\section{SUMÁRIO}

1. Introdução. 2. Crítica ao pensamento punitivo. 3. A reincidência e suas implicações quando agravante da pena. 4. Efeitos extrapenais da reincidência e propostas de superação. 5. A consideração da reincidência na dosimetria da pena na cidade de campinas. 6. Considerações finais. 7. Referências.

\section{Resumo}

O presente trabalho utiliza-se de pesquisa teórica e de julgados para tratar sobre o instituto da reincidência, principalmente no tocante a sua aplicação como agravante da pena, evidenciando como ele tem sido empregado aos condenados na cidade de Campinas-SP. Para isso, perpassam-se as convicções acerca do controle social formal e informal, do sistema penal e seu viés punitivista, e de sua relação direta com o instituto da reincidência, abordando este conceito e suas principais características, bem como suas implicações quando agravante da pena e suas mencionadas contradições com o Regime Democrático de Direito, tudo sob a ótica da Criminologia Crítica. Discute-se, igualmente, os efeitos processuais penais e extrapenais que esta agravante da pena acarreta, tendo como enfoque o estigma que recai sobre o reincidente. Apresentamos, assim, uma pesquisa de julgados acerca da consideração da reincidência na dosimetria da pena na cidade de Campinas-SP, entre os meses de agosto e setembro de 2016, abordando os índices resultantes desse estudo e os comparando a outros já realizados. Em conclusão, ressalta-se que, posteriormente ao apontamento das críticas proferidas à reincidência, há a exposição de propostas de sua superação, como sua aplicação como atenuante da pena ou sua total eliminação do ordenamento jurídico. 


\title{
ESTUDYING RECIDIVISM IN CAMPINAS'S CITY
}

\author{
Fernanda Carolina de Araujo Ifanger \\ Nathália Bortoletto Gravina
}

\section{Key-words}

criminology / criminal law / social control / recidivism / Campinas

\section{Abstract}

The present work employs theoretical and jurisprudential researches to approach the recidivism institute, focusing mainly in its appliance as a sentence aggravating factor, highlighting the way it has been employed to convicts in the city of Campinas-SP. For such task, it runs through convictions on formal and informal social control, the criminal system's punitivist focus and its straight relationship with the recidivism institute, approaching such institute and its main characteristics, as well as its implications when employed as a sentence aggravating factor and its contradictions with the Democratic Regime of Law, all under the optic of the critical criminology. Likewise, the article discusses the criminal proceeding and extrapenal effects caused by such sentence aggravating factor, focusing on the stigma that falls over the recidivist. Hence, we present a research on the way recidivism has been taken into account in Court decisions in the city of Campinas-SP between the months of august and september 2016, approaching the indexes resulting from such study and comparing it with other previous studies on the matter. Concluding, we point out that after indicating such criticism to the recidivism, the work exposes proposals for its overcoming, its application as a sentence mitigation factor or its complete elimination from the legal order. 


\section{INTRODUÇÃO}

A reincidência criminal é objeto de numerosos estudos contemporâneos. A aspiração de discorrer sobre o tema justifica-se, principalmente, pela grande incidência de reincidentes penitenciários. Somente no Brasil, a taxa apresentada pelo IPEA (Instituto de Pesquisa Econômica Aplicada) é de 24,4\%, enquanto a revelada pelo DEPEN (Departamento Penitenciário), em 2001, de 70\%. Embora haja ampla disparidade entre os índices divulgados, é inegável que os números da reincidência são bastante elevados e evidenciam que a prática delituosa reiterada entre os condenados é comum.

Conquanto as penas impostas pelo Direito Penal devam buscar a readaptação do condenado à vida em liberdade, a reincidência parece marcá-lo definitivamente e fazer com que o seu crime anterior seja sempre lembrado, empurrando o indivíduo, cada vez mais, de volta ao sistema penal. Fato é que a reincidência se cola ao indivíduo como um estigma e, a partir disso, o sistema penal o verá como alguém que não é digno de confiança, que não merece ser acreditado, já que é um "criminoso".

Na visão de Zaffaroni (1996), a reincidência representa a opção por um direito penal autoritário, razão pela qual é necessário refletir sobre sua existência.

Assim, diante da importância do tema, o presente trabalho objetiva refletir, a partir da criminologia de viés conflitual, identificada pelas teorias do labelling approach e crítica, representadas por autores como Goffman, Zaffaroni, Becker, Lemert, Baratta, entre outros, acerca da reincidência, com destaque para o fato de ela ser prevista na legislação penal como agravante de pena.
Também será apresentado um estudo de julgados acerca da reincidência como agravante de pena, na cidade de Campinas, visando a identificar os posicionamentos adotados pelos magistrados atuantes no município acerca da reincidência como agravante da pena imposta. Em razão da grande quantidade de decisões encontradas, a análise restringiu-se ao período temporal de agosto e setembro de 2016, resultando em um universo de 155 julgados examinados.

Buscou-se, com essa análise, entender como as Varas Criminais de Campinas têm compreendido e considerado o instituto da reincidência; se os juízes do município a têm utilizado para agravar a pena do autor do crime; em caso afirmativo, buscou-se identificar o montante da exasperação no caso concreto, uma vez que não há limites pré-estabelecidos para o aumento; e, por fim, compreender se os magistrados têm interpretado a reincidência de maneira crítica, de modo a não aplicá-la no caso concreto ou mesmo a utilizá-la para atenuar a pena imposta na sentença.

\section{CRÍTICA AO PENSAMENTO PUNITIVISTA}

Com a necessidade dos indivíduos de viverem em sociedade, tornou-se imprescindível o exercício de um controle para evitar o caos e garantir a convivência pacífica entre todos. Através de regras comportamentais emanadas do Estado, ou da sociedade civil e suas instituições, esse mecanismo de contenção é efetivado.

Denominado de controle social, esse fator limitante pode ser realizado de maneira formal ou informal, de acordo com os agentes encarregados da realização da função fiscalizadora das condutas. O controle social 
formal é exercido, predominantemente, pelas autoridades estatais, enquanto o controle social informal o é pelos grupos sociais, como a escola, a família, os amigos e a vizinhança (Sabadell, 2013).

Os estudos criminológicos, desde o seu surgimento, por meio da Escola Clássica e depois da Escola Positivista, buscaram entender a relação dos indivíduos com o crime, seja por meio da compreensão teórica do delito, seja por meio do estudo do criminoso, respectivamente, sem, contudo, problematizar a atuação das agências encarregadas da persecução penal, ou seja, o exercício do controle social formal por elas realizado.

Somente mais tarde, na década de 1960, com o surgimento da criminologia de matiz conflitual, especificamente as teorias do labelling approach e crítica, é que o citado exercício passou a ser questionado, por entender-se que sua atuação é fundamental para a própria criação da criminalidade e que ele não é neutro.

Pode-se entender que as teorias conflituais "Iocalizam as verdadeiras variáveis do processo de definição e seleção nas relações de poder dos grupos sociais, partindo do dado da estratificação social e dos conflitos de interesses" (García-Pablos de Molina, 1986, p. 343).

Assim, a partir desse pressuposto, não se pode mais aceitar a ideia de que o sistema penal atua de maneira igualitária com o objetivo precípuo de combater o crime que acontece em todas as camadas da sociedade, uma vez que a sua característica fundamental é a seletividade.

Nesse ponto, Santos destaca a tensão entre a aparência de um processo e a realidade do exercício seletivo do poder de punir com as seguintes palavras: a) o discurso jurídico destaca o processo legal devido, redigido pela dogmática penal e processual penal como critério de racionalidade, define o crime como realidade ontológica preconstituída e apresenta o sistema de justiça como instituição neutra que realiza uma atividade imparcial, b) a criminologia crítica revela o processo legal devido como exercício seletivo do poder de punir, mostra o crime como qualidade atribuída a determinados fatos, a criminalização como um bem social negativo distribuído desigualmente e, funalmente, o sistema de justiça criminal como instituição ativa na transformação do cidadão em criminoso (Santos, 2002, p. 55).

Toda a criminologia crítica produzida a partir desse momento, nas suas mais diversas perspectivas, tais como o direito penal mínimo e o abolicionismo penal partem dessa premissa, ainda que suas propostas de superação sejam bastante diversas.

Nesse diapasão, a crítica ao punitivismo realizada nesse excerto, tem por base esse pensamento e enxerga o conflito social como instrumento da dominação e coerção.

Para Sabadell (2013, p.128) o controle social possui um significado muito vasto, pois

indica todo processo de socialização que orienta o indivíduo, integrando-o aos valores e aos padrões de comportamento social. Por esta razão, o controle social está intimamente relacionado com os conceitos de "poder" e de "dominação política", que criam determinada ordem social e integram os indivíduos nela.

Por esse entendimento, o controle social, precipuamente o institucionalizado, induz os indivíduos a se comportarem consoante 
o sistema e a respeitarem os detentores do poder, que invariavelmente, são os titulares de riqueza. Nesse sentido, então, o Direito Penal não é instrumento que objetiva a promoção da convivência harmônica entre os cidadãos por meio do reconhecimento da igualdade de todos, mas sim ferramenta que busca a manutenção da estratificação social, favorecendo diretamente as camadas mais ricas da população em detrimento das mais carentes (Sabadell, 2013).

Zaffaroni (2001, p. 182) retrata essa verticalização social propiciada pelo Direito Penal ao versar que

(...) o exercício de poder verticalizante próprio da sociedade industrial - é racionalizado através do discurso justificador do direito penal, que cumpre uma função legitimante, não da agência judicial, mas de todo o sistema penal. A transculturação neocolonialista, própria da característica modernizadora incorporativa da civilização industrial, trouxe o discurso jurídico-penal para a periferia, onde, até hoje, os mesmos discursos legitimantes são utilizados, apesar do diversificado exercício de poder dos sistemas penais marginais.

Por conseguinte, o Direito Penal é uma espécie de controle institucionalizado que utiliza o seu poder punitivo de forma discriminatória, dado que, por meio do cárcere, oprime as minorias culturais, os negros, os jovens e os pobres (Garland, 2008). ${ }^{3}$ Sendo assim, ao fazer incidir a pena sobre as classes mais baixas, impede sua ascensão social e mantém a escala vertical da sociedade (Baratta, 2002).

\footnotetext{
${ }^{3}$ Ainda que os estudos realizados pelo autor tenham como referência a situação do controle social nos Estados Unidos e Reino Unido, im portante mencionar que os dados do Infopen (2017) indicam que a população prisional é composta majoritariamente por jovens, sendo que os presos até 29 anos representam 54\% desse universo e que os pretos e pardos representam 63,6\% da população presa.
}

Conforme Baratta (2002, p.166),

(...) não só as normas do direito penal se formam e se aplicam seletivamente, refletindo as relações de desigualdade existentes, mas o direito penal exerce, também, uma função ativa, de reprodução e de produção, com respeito às relações de desigualdade.

Sua influência direta nas relações de desigualdade, deve-se, sobretudo, a seu método de seleção. O sistema penal segrega indivíduos em conformidade com os estereótipos disseminados pelos meios de comunicação de massa, e não em observância somente dos atos praticados, permitindo a rotulação dos agentes segundo a imagem concebida do criminoso e excluindo os sujeitos que realizam crimes de trânsito, colarinho branco, etc. (Zaffaroni, 2001). Destarte os grupos que formam a população carcerária são compostos substancialmente por indivíduos desvalidos e que nunca tiveram seus direitos assegurados (Ifanger; Poggetto, 2016).

A necessidade de punir esses indivíduos díspares, segregando-os, deve-se à inexistência de identificação entre a sociedade e o criminoso, pois, consoante Becker (2008, p. 16),

(...) encaramos uma pessoa que comete uma transgressão no trânsito ou bebe um pouco demais numa festa como se, afinal, não fosse muito diferente de nós, e tratamos sua infração com tolerância. Vemos o ladrão como menos semelhante a nós e o punimos severamente. Crimes como assassinato, estupro ou traição nos levam a ver o transgressor como um verdadeiro outsider. ${ }^{4}$

${ }^{4}$ É possível entender como outsiders qualquer pessoa que presumivelmente infringe regras impostas a ela. Isto é, um indivíduo que a sociedade, conscientemente, não espera que viva conforme as suas regras (Becker, 2008). 
Contudo, em realidade, o criminoso não é tão diferente do não criminoso, uma vez que, de acordo com Baratta (2002), todos os indivíduos têm impulsos para atitudes criminosas, mas elas, muitas vezes são inibidas pelo superego, e o sentimento de culpa em razão delas existirem justificaria o insulto e a punição, por parte da população, para os que não conseguiram se controlar.

Além disso, conforme assevera Santos (2004), a violência erigiu-se ao posto de uma nova questão social global, o que tem provocado mudanças no estado de controle repressivo, cujas características passam a ser a produção social do sentimento de insegurança; o controle social do crime não é mais apenas das agências estatais, mas também das polícias privadas; o encarceramento dos "consumidores falhos", com o consequente abandono de ideias correcionais; o discricionarismo e a violência policial.

Em razão dessa lógica, diversos dispositivos penais que ferem preceitos constitucionais mantêm suas forças por meio do discurso punitivista de preservação da segurança pública. Não importa se o direito individual do suposto criminoso está sendo desrespeitado, se está sendo ferida a sua condição de pessoa humana, se a pena lhe retirará a sanidade mental, desde que os "cidadãos de bem" sejam protegidos, ou, pelo menos, tenham essa sensação.

Isso ocorre também com os instrumentos estatais, como a prisão, que "é usada atualmente como um tipo de reservatório, uma zona de quarentena, na qual indivíduos supostamente perigosos são segregados em nome da segurança pública" (Garland, 2008, p. 381).

Barroso (2009, p. 79) retrata essa percepção claramente ao discorrer sobre os maus antecedentes criminais, sintetizando que
(...) quando uma pessoa é condenada por sua folha de antecedentes, ou seja, pela "inclinação que essa tem para o delito", resta evidente a manifestação de um direito penal do inimigo, em que o Estado, sem fundamento, alega que o sujeito é um ente perigoso ou marginal e que, portanto, deve permanecer enjaulado, para evitar o cometimento de delitos futuros logo, mero mecanismo de contenção de uma pessoa.

A razão dessa escusa punitiva é demonstrada por Garland (2008, p. 377) quando evidencia que a prioridade do processo criminal é tratar as consequências do crime e não as suas causas, visto que "em vez de enfatizar em métodos de reabilitação que atendam às necessidades do criminoso, o sistema enfatiza controles efetivos que minimizem os custos e maximizem a segurança". Ou seja, por mais que o Estado afirme que a finalidade da pena é a ressocialização dos criminosos, poucos esforços têm sido direcionados a esse objetivo, ao contrário, a execução penal "pode provocar um processo ressocializador às avessas, redundando numa total e absoluta dessocialização" (Franco, 2010, p.6).

Essa situação fica evidente quando se trata da realidade carcerária brasileira, pois "muito ao contrário do sustentado objetivo teórico das finalidades da pena e prisões, o que se verifica é que a cadeia perverte, corrompe, deforma, avilta, embrutece, despersonaliza, e, portanto, não cumpre com seus reais deveres" (Vilas Boas, 2003, p. 14).

Isto posto entende-se que o Direito Penal é uma forma de controle social institucionalizado, e como todo controle, utiliza-se de um aparato repressivo para restringir direitos e violar normas, fundamentando-se na manutenção da segurança pública. Sua "preo- 
cupação principal é administrar o espaço e separar os diferentes tipos de pessoas" (Garland, 2008, p. 345). Nesse sentido, o propósito do Direito Penal não é somente punir, mas selecionar quem punir (Berla, 2010).

Evidenciadas as críticas ao pensamento punitivo que se constituiu por meio do sistema penal, cabe ater-se, no excerto seguinte, à reincidência produzida por esse sistema, e que se consubstancia em um dos instrumentos de controle criminal, demonstrando como ocorre a sua aplicação e salientando o viés punitivo mascarado nesse instituto, razões que justificam a sua não preservação como agravante no ordenamento jurídico brasileiro.

\section{A REINCIDÊNCIA E SUAS IMPLICAÇÕES QUANDO AGRAVANTE DA PENA}

No momento em que um magistrado elabora uma sentença penal condenatória, é seu dever realizar a dosimetria da pena, isto é, definir o prazo de cumprimento da sanção imposta ao condenado. Para efetuar esse cálculo, é preciso observar o procedimento exposto no art. 58 do Código Penal brasileiro, que exige a análise da pena base, das circunstâncias atenuantes e agravantes, e das causas de diminuição e aumento de pena.

No que concerne às circunstâncias agravantes e atenuantes, estão previstas em hipóteses taxativas elencadas nos arts. 61 e 62, respectivamente, do Código Penal brasileiro, e têm relação, na sua maior parte, com o crime praticado, à exceção da reincidência, que se refere exclusivamente a uma condição pessoal do autor do crime. Em razão da sua importância e de suas peculiaridades, é esta a agravante genérica que será objeto deste estudo.

Conforme o Código Penal brasileiro, em seu art. 63 "verifica-se a reincidência quando o agente comete novo crime, depois de transitar em julgado a sentença que, no País ou no estrangeiro, o tenha condenado por crime anterior" (Brasil, 1940).

Percebe-se que a legislação determinou em qual conjuntura esse instituto se consubstancia, mas foi omissa quanto à presença dos elementos subjetivos do tipo, permitindo entender que reincidente é quem pratica um crime posterior, independente se culposo ou doloso. Também, que a agravante em questão é denominada genérica, pois não importa se o segundo delito cometido foi idêntico ao primeiro, bastando, portanto, a realização de qualquer outra infração penal para configurar a reincidência (Freitas, 2009).

Segundo o art. 64 do Código Penal brasileiro, a reincidência possui um período depurador de cinco anos, ou seja, um indivíduo só não será considerado reincidente se entre a data do cumprimento ou extinção da pena anterior e a infração posterior tiver decorrido um período de tempo superior a cinco anos. Schaffa (2009, p. 10) observa que

(...) no Brasil, a pena nunca termina ao fim da execução. Naturalmente ela se prolonga por mais 5 anos. Durante este "período de prova", a pena já cumprida fica à espreita, esperando o momento certo pra reaparecer. Isto porque o legislador brasileiro acredita que, não funcionando a reabilitação na primeira passagem pelo cárcere, é necessário garantir que o reincidente seja novamente encaminhado para prisão e que lá fique mantido por mais tempo.

Importante asseverar que nos dois dispositivos legais mencionados, não fica claro a partir de que momento o indivíduo pode ser considerado reincidente. Ao utilizar-se das expressões "agente comete novo crime" 
(art. 63, CP) e "infração posterior" (art. 63, CP), a lei não evidencia se a data a ser considerada é a da prática do novo crime ou o momento da prolação da sentença definitiva que condena o agente por este ilícito. Isso faz com que muitos magistrados entendam que a existência de condenação anterior é suficiente para permitir o agravamento da pena já na sentença de primeira instância.

Quanto à classificação da reincidência entre ficta e real, a legislação brasileira admite o primeiro tipo, pois o que será analisado é se houve uma condenação anterior com trânsito em julgado e não se a pena imposta foi efetivamente cumprida (Berla, 2010). Isto é, um indivíduo será considerado reincidente se cometer um crime após o trânsito em julgado da sentença penal condenatória, mesmo que não tenha cumprido integralmente a pena imposta em sua condenação.

Indene de dúvidas que o sistema penal brasileiro adota a reincidência de forma a proporcionar uma maior punição ao apenado. Trata-se da imposição de um castigo adicional para aquele que decide, mais uma vez, desrespeitar a legislação penal. É visível essa situação ao observar que, embora esse instituto seja conhecido por majorar a pena imposta ao agente, ele ocasiona uma série de outros efeitos subsidiários que agravam a situação jurídica do condenado, conforme demonstra Berla (2010, p. 305):

(...) além de funcionar como agravante, a reincidência exerce importante papel como fator impeditivo de conferência de benefícios ao acusado durante todo o decorrer do processo penal e após este, desde o inquérito policial até a execução da pena imposta.

Fato é que a reincidência "se faz presente na legislação brasileira em 29 momentos.
Agravar a pena, impedir ou revogar benefícios e alterar prazos são suas principais funções" (Schaffa, 2009, p. 10). Entre os numerosos efeitos subsidiários ao acréscimo de pena destacam-se os seguintes: a reincidência é um fator preponderante na contraposição entre agravantes e atenuantes; ela interfere diretamente na fixação do regime (art. 33); veda a concessão de fiança (art. 323, III); proíbe a diminuição ou substituição da pena, como a mudança de pena restritiva de liberdade por restritiva de direito/multa (art. 44, II e art. 60); proporciona o aumento do prazo prescricional e o interrompe e, por fim, eleva os prazos para concessão de saída temporária e do livramento condicional (art. 83, II).

Especificamente, ao aplicar a reincidência como instituto agravante da pena, fazendo emergir seus efeitos legais, impede-se, ou ao menos se dificulta que o apenado cumpra penas alternativas à prisão, o que favorece diretamente o encarceramento, atrasa seu retorno ao convívio social e fortalece seus laços com as atividades criminais, criando um ciclo vicioso do qual dificilmente o indivíduo consegue esquivar-se (Freitas, 2009). 5

Ademais, sua consideração como agravante da pena viola diversos princípios do Direito Penal e da Constituição Federal, razão pela qual autores como Teixeira (2014), Franco (2010) e Freitas (2009) defendem a ilegitimidade de seu reconhecimento. Esse posicionamento analítico é justificado pela estruturação do ordenamento jurídico brasileiro que deve submeter suas normas aos princípios supralegais.

5 Outro fator que influencia diretamente esse ciclo vicioso encontra-se exposto no art. 482 da CLT, que determina a possibilidade da despedida por justa causa ao empregado que for condenado definitivamente por uma sentença penal. Assim, verifica-se, novamente, a dificuldade do condenado de retornar a sua vida pregressa, pois além de possuir antecedentes criminais, terá em seu registro de trabalho mais um elemento para dificultar o seu retorno ao labor e, consequentemente. o seu sustento. Minguadas as oportunidades de retorno ao mercado de trabalho formal, o crime se apresenta, mais uma vez, como uma alternativa à vida após o cárcere. 
Freitas (2009), referindo-se ao princípio do Estado Democrático de Direito versa, conjuntamente, sobre essa hierarquização entre as normas, ao asseverar que existe Estado Democrático de Direito à medida que - Direito Penal se submete aos princípios constitucionais penais. Devido à supremacia das normas, o Direito Penal obriga-se a observar e respeitar os princípios constitucionais penais, pautando-se por eles e nunca os contrariando, sob pena de alegação de inconstitucionalidade e invalidação dos atos praticados.

À luz dessa perspectiva, é possível identificar claramente diversas violações principiológicas decorrentes da reincidência.

Ao analisar a existência dessas violações na esfera constitucional, nota-se que a majoração de pena imposta ao reincidente desrespeita uma regra basilar de punição adotada pelo sistema penal brasileiro, denominada de direito penal do fato, que determina que um indivíduo deva ser condenado pelo fato típico e ilícito que praticou, conforme tratam os princípios da legalidade e da culpabilidade (Teixeira, 2014). Entretanto, se examinados os critérios de aplicação dessa agravante, é perceptível que o acréscimo de pena imposto "não mais teria como fundamento algo que o autor fez, mas sim a sua condição de vida, sua personalidade. Tal apenação baseada na vida pregressa do indivíduo seria típica de um direito penal do autor, antiliberal" (Teixeira, 2014, p. 108) e distinta da condenação imposta pelas normas do sistema penal.

Este pensamento que consubstancia o direito penal do autor está ligado à ideia lombrosiana de que os criminosos são pessoas diferentes das demais e, em razão disso, merecem receber um tratamento diferenciado durante toda a sua vida, enquanto não haja cura para o mal da criminalidade.

De forma a sintetizar o preceito ora em análise, Freitas (2009, p. 132) afirma que "tratando-se o direito penal brasileiro de um direito penal do fato e não de um direito penal do autor, só podemos reprovar o agente pelo o que ele fez (culpabilidade do ato) e não pelo que ele é (culpabilidade do autor)".

Do mesmo modo, a reincidência desrespeita o valoroso princípio da dignidade da pessoa humana, "porque a agravação implica punição pelo que se é e não pelo que se fez, traduzindo-se, pois, em ingerência no foro íntimo, na intangível esfera da personalidade protegida pelo postulado da dignidade humana (art. 1, III, da CF)" (Ibccrim, 2014, p. 557).

Ademais, observa-se que essa punição mais rigorosa imposta ao reincidente o coloca em posição inferior em relação aos demais cidadãos, ferindo o princípio da igualdade e podendo, inclusive, gerar estigmatização (Ibccrim, 2014).

Ressalta-se, ainda, que as consequências geradas com a aplicação desse instituto, tais como o aumento da pena, o estigma de reincidente e as alterações que provoca na execução da pena, são consideradas demasiadamente penosas ao condenado e acarretam em mais uma violação, dessa vez, ao princípio da proporcionalidade ou da razoabilidade, que proíbe a desproporção entre o meio e o fim da pena (Ibccrim, 2014).

Já no âmbito da legislação penal, a insubordinação ao princípio ne bis in idem é a mais aludida, pois ele determina a vedação da dupla incriminação pelo mesmo fato ou circunstância, entretanto, "ao estabelecer aumento de pena por fato anterior processado, julgado e punido" (Ibccrim, 2014, p. 548), 
faz-se exatamente o que o princípio vedou.

Freitas (2009, p.125) complementa esse entendimento ao defender que

(...) se um indivíduo comete um delito, sendo julgado e condenado em definitivo e se este mesmo indivíduo pratica posteriormente outro fato punível que acarreta o aumento na quantidade de pena que Ihe é aplicada, a partir da consideração não do segundo delito, mas do primeiro, pelo qual já foi julgado e condenado, existe violação ao mencionado princípio constitucional penal.

Por fim, Franco (2010, p. 5) sintetiza todas as considerações anteriormente apontadas ao afirmar a incompatibilidade absoluta da reincidência com as normas constitucionais, pois para ele:

(...) trata-se, aqui, do princípio da manifesta soberania da Constituição, que estando no ápice de todo o ordenamento jurídico, tem inquestionável primazia em relação à lei ordinária que lhe é anterior. Isto não quer dizer que toda legislação precedente a uma nova Constituição Federal esteja automaticamente revogada, mas, sim, que toda legislação anterior, que com ela confronte, não poderá subsistir. Ora, no caso do instituto da reincidência, ficou patente a sua total incoerência com os preceitos fundamentais da Constituição Federal de 1988 e, por isso, não foi por ela recepcionado.

Isto posto, com as particularidades do instituto elencadas, nota-se que ao aplicá-lo como agravante da pena ferem-se dispositivos constitucionais e penais, além de proporcionar ao condenado uma punição injustificada.

Não obstante as críticas aqui apresentadas acerca do agravamento da pena em razão da reincidência, outras, de vieses criminológicos, serão a presentadas no próximo excerto, as quais podem sinalizar a necessidade de superação da ideia de tratamento legal mais gravoso para o reincidente.

\section{EFEITOS PENAIS E EXTRAPENAIS DA REINCIDÊNCIA E PROPOSTAS DE SUPERAÇÃO}

Além de todas as implicações penais e processuais que produz, a reincidência também estende seus efeitos para além do sistema penal, influenciando o olhar social sobre o reincidente e a forma como ele enxerga a si mesmo.

Carvalho (2001, p. 111), esclarecendo a visão da criminologia da reação social sob a reincidência vai defender que

(...) o rótulo da reincidência estabeleceria papéis e estigmas - perverso, inadaptado, perigoso, hediondo -, gerando expectativas do público que consome o sistema penal. Tal expectativa atua nitidamente como influência, potencializando o comportamento futuro do 'reincidente'. Criar-se-iam novos status nas relações em sociedade, e o 'crime' é também um status (negativo), que tendem a negar a finalidade oficial da pena - ressocialização.

Ao considerar um indivíduo reincidente, imputa-se a ele o estigma de criminoso, o que causa diversas repercussões nocivas à sua pessoalidade, tais como a insegurança de não saber o que outros indivíduos pensam sobre ele, o receio de ser julgado por seu atributo e o sentimento de exposição que faz com que seus menores atos são considerados notáveis e extraordinários (Goffman, 2008). 
Em razão da negatividade do seu rótulo, a sociedade visualiza de forma distinta o indivíduo comum e o estigmatizado, porque,

por definição, é claro, acreditamos que alguém com um estigma não seja completamente humano. Com base nisso, fazemos vários tipos de discriminações, através das quais efetivamente, e muitas vezes sem pensar, reduzimos suas chances de vida: construímos uma teoria do estigma; uma ideologia para explicar a sua inferioridade e dar conta do perigo que ela representa, racionalizando algumas vezes uma animosidade baseada em outras diferenças, tais como as de classe social. Utilizamos termos específicos de estigma como aleijado, bastardo, retardado, em nosso discurso diário como fonte de metáfora e representação, de maneira característica, sem pensar no seu significado original (Goffman, 2008, p. 8).

Nesse sentido, para tornar palpável o que o estigma representa, Goffman (2008) narra a ocasião em que um observador se impressiona ao se deparar com um criminoso profissional lendo livros escritos por Claude Cockburn, Hugh Ware, Simone de Beauvoir e Lawrence Durre, já que se espera que um criminoso se interesse por novelas e bibliografias sensacionalistas. O espanto do observador pode até ter sido natural, mas afeta o criminoso como um insulto, visto que após ter cometido um delito, a sociedade não o enxerga mais como um ser humano.

Isto posto, é cognoscível que o estigma rotula e aparta indivíduos quando permite que recaia sobre eles um adjetivo que determina que são pessoas ruins, já que serve de elemento para distinguir negativamente alguém, degradando publicamente o seu caráter. É como se a sociedade emitisse um alerta sobre as pessoas com as quais você deve ou não se relacionar, instigando o preconceito e dificultando ainda mais a interação social dos vitimados. Assim, pessoas estigmatizadas tendem a se relacionar com outros indivíduos que sofrem ou já sofreram a estigmatização, reduzindo ainda mais o seu ciclo de convivência.

É exatamente esse fenômeno que atinge o "criminoso", nos contatos sociais que estabelece com o "não criminoso". Apesar de, em muitos casos, já ter cumprido a sua pena e ter se submetido a todas as exigências impostas pelo sistema de controle, precisa esforçar-se para esconder o seu estigma, que fornece uma informação social destrutiva a seu respeito, optando, muitas vezes, por estabelecer relações sociais superficiais ou baseadas em dados inventados.

Sob essa ótica, fica evidente que o reincidente sofre uma dupla penalização, pois além de ser responsabilizado criminalmente por seu delito, é punido também pela sociedade que o exclui, intitulando-o como um representante de um perigo e um mal que não pode ser remediado; restando-Ihe apenas o encarceramento.

Em vista disso, o instituto da reincidência mostra ser mais uma escusa do Estado em relação à ineficácia da finalidade da pena, que mesmo demonstrando sua incapacidade de ressocialização, culpa o criminoso por reincidir e o pune ainda mais.

Garland (2008, p. 384), através da teoria do controle, agrega esse posicionamento e explana a razão dessa maior punição ao reincidente:

Atualmente, os interesses dos criminosos condenados, quando levados em consideração, são vistos essencialmente como 
opostos ao público. Se a escolha é entre sujeitar criminosos a maiores restrições ou o público a riscos mais elevados, o senso comum vigente sempre recomenda a escolha segura. Consequentemente, sem muita discussão, os interesses dos criminosos e mesmo seus direitos são frequentemente desconsiderados.

Há que se destacar ainda, consoante apresentado no excerto 2 , que o sistema penal é seletivo. Por não ter condições de atuar para investigar e punir todos os crimes que acontecem em dada sociedade, é possível afirmar que a seleção criminal obedece a filtros e que ser reincidente facilita sobremaneira uma nova captura do indivíduo pelo sistema penal. Sendo assim, para o reincidente, estar no lugar errado e na hora errada pode ser fatal, uma vez que toda a ação do sistema penal é guiada a partir do signo trazido pelo rótulo que o agente ostenta. A reincidência pode, assim, transformar um transeunte que ia em direção ao seu trabalho em suspeito principal do crime cometido na região.

Para a teoria do labelling approach a reincidência é o caminho natural de quem passa pelo sistema penal, o que justificaria os grandes índices de reincidência mencionados no início do texto e que serão melhor discutidos no próximo excerto, uma vez que ela pode implicar numa transformação pessoal do reincidente.

Conforme mencionado, a experiência do contato com o sistema penal cola-se ao indivíduo como uma etiqueta que o identifica e o diferencia dos demais. A partir dela, toda a sua interação social precisará ser cuidadosamente pensada, a fim de não revelar seu estigma, bem como afetará a imagem que o indivíduo tem de si mesmo. Reduzidas, pois, as suas possibilidades de ação e compreensão de si mesmo, resta ao indivíduo somente fazer o que seu estigma Ihe permite: delinquir.

Este processo que se encerra com a recidiva no crime é denominada, por Lemert, de desviação secundária. Segundo o autor,

(...) quando uma pessoa começa a empregar seu comportamento desviante ou um papel baseado sobre ele como um meio de defesa, ataque, ou ajustamento aos problemas públicos ou encobertos criados pela reação social a ele, sua desviação é secundária (Lemert, 1951, p. 76).

Lemert (1951) evidencia que até a desviação secundária inicia-se com a desviação primária; após ela têm lugar as reprimendas sociais; mais desviação primária ocorre; reprimendas mais rigorosas e rejeições são impingidas contra o desviante; mais desviação, e talvez sensações de hostilidade e início de ressentimento do autor contra os que o penalizam são passiveis de aparecer; inicia-se uma crise do quociente de tolerância, expressa por meio de ações formais da comunidade estigmatizando o desviante; após isso se fortalece a conduta desviante como reação à estigmatização e às penalizações insurgidas contra o autor do desvio; e, por fim, ocorre a última aceitação do status desviante e a realização de esforços do autor para ajustar-se ao papel a ele associado.

Sendo assim, resta claro que a reincidência é estimulada pelo próprio sistema penal e pela reação social, ao limitar sobremaneira as possibilidades de inserção social do indivíduo que teve algum contato com o crime ao longo de sua vida.

A fim de superar os males causados por essa agravante, estudiosos sugeriram alternati- 
vas quanto a sua aplicação. Vargas (2009, p. 24), por exemplo, propõe que a reincidência seja considerada como um instituto atenuante da pena, pois para ele:

é possível afirmar que não foi recepcionado pela CF/88 o art. 61, I, do CP, o qual insere a reincidência como circunstancia que agrava a pena, bem como todas as restrições a direitos, aplicadas com a segunda condenação. Além disso, o art. 63 do CP deveria ser revisto para abarcar apenas a reincidência real, e esta deveria passar a constar expressamente no rol das circunstancias atenuantes.

Tangerino (2014, p. 214) compactua com esse parecer, porque, segundo ele, "ao contrário do que geralmente afirmado pela doutrina, pode a reincidência denotar menor culpabilidade do agente (e não maior) reclamando como medida adequada à atenuação da reprimenda e não a exasperação".

Franco (2010), por sua vez, entende ser incabível em um Estado Democrático e Social de Direito que a reincidência continue no rol de agravantes obrigatórias, segundo ele, esse instituto deveria ser excluído da legislação brasileira. Entretanto, nos casos em que sua recepção persistisse, ele deveria ser considerado como uma circunstância atenuante inominada.

Freitas (2009) também sustenta essa hipótese ao recomendar a revogação do art.63 do CP e de todos os seus correlatos. Consoante o autor, espera-se ao menos a existência de um programa reformista para reparar os aspectos nocivos desse instituto e revogar seus efeitos legais.

Almeida (2013, p. 61), todavia, não só discorre sobre a necessidade de eliminar a reincidência como circunstância agravante, mas apresenta possíveis soluções para a redução do número de reincidentes:

Para além do afastamento do discrepante e maniqueísta instituto da reincidência em sede de controle difuso ou concentrado de normas, faz-se mister a concretização de medidas racionas como a reforma do espaço físico das penitenciárias, a humanização do sistema, a implementação de políticas de reinserção social, a ampliação e aplicação de penas alternativas, entre outros, afim de evitar a reincidência. Não obstante, em caráter urgente, é de relevante importância a supressão de certas informações constantes na certidão de antecedentes criminais ao público, no propósito de viabilizar a reintegração do egresso ao meio social.

Destarte, não sobejam dúvidas de que as implicações geradas por esse instituto são mais profundas do que quer demonstrar a legislação penal. Deve-se, portanto, enxergá-lo além de sua conjuntura meramente dogmática, acrescendo a sua análise elementos da crítica criminológica, para que assim, reflexões acerca da necessidade de sua conservação no ordenamento, bem como as modificações na legislação que trata sobre o tema sejam mais condizentes com as consequências produzidas pela reincidência.

Apresentadas as críticas ao instituto, adiante se salientará como a reincidência tem sido aplicada para agravar a pena do condenado nos casos concretos, demonstrando-se se as apreciações feitas ao seu respeito têm ou não reflexo nas sentenças judiciais penais.

\section{A CONSIDERAÇÃO DA REINCIDÊNCIA NA DOSIMETRIA DA PENA NA CIDADE DE CAMPINAS}


Evidenciadas as críticas ao instituto da reincidência, deu-se início a uma pesquisa de decisões judiciais com o propósito de compreender como os magistrados da cidade de Campinas têm se manifestado em relação à aplicação da reincidência como agravante da pena.

Especificamente, buscou-se saber se os juízes têm utilizado a reincidência para agravar a pena do condenado, tal qual previsto em lei e, em caso afirmativo, o montante desse aumento. Ademais, objetivou-se verificar se as críticas dogmáticas, principiológicas e criminológicas dirigidas ao instituto encontraram ressonância nas decisões proferidas.

O estudo foi realizado por meio do endereço eletrônico do Tribunal de Justiça do Estado de São Paulo (TJSP), com a consulta de julgados de primeiro grau, advindos das Varas Criminais da cidade de Campinas, no período de 01/08/2016 a 30/09/2016, utilizando-se como palavra-chave buscada o termo "reincidência".

Desde o início dessa fase da pesquisa chamou a atenção a grande quantidade de julgados em que o termo escolhido como critério de busca foi encontrado, o que causou a necessidade de eleição de um marco temporal relativamente exíguo - 01/08/2016 a 30/09/2016. - que contemplasse um número de decisões que pudessem ser efetivamente analisadas pelas pesquisadoras.

A princípio foram encontrados 178 (cento e setenta e oito) processos, todavia, ao analisá-los foi possível notar que julgados de competência material/territorial distinta da determinada apareceram no resultado da busca, e como eles não fazem parte do objeto de pesquisa, não foram apreciados. Também houve processos que possuíam o termo "reincidência" presente no corpo da sentença, mas o réu não foi considerado efetivamente reincidente, razão pela qual dessas decisões também foram desconsideradas. Por fim, após a observação de todos os resultados encontrados, 155 (cento e cinquenta e cinco) julgados foram examinados.

Pertinente salientar que no período escolhido para a realização da pesquisa houve 535 (quinhentos e trinta e cinco) processos que não tiveram réus reincidentes e 155 (cento e cinquenta e cinco) julgados que possuíram réus reincidentes, logo, a porcentagem de reincidentes encontrada nesse lapso temporal configura-se em torno de $28,97 \%$.

Das 155 (cento e cinquenta e cinco) decisões proferidas, 39 (trinta e nove) reconheceram a reincidência como circunstância agravante, mas sua consideração não implicou no aumento do montante da pena por ter sido compensada pela presença de uma atenuante. Dessa totalidade, em 2 (dois) processos os magistrados compensaram a reincidência com a atenuante referente à idade, prevista no art. 65, inciso I, do Código Penal. Nas demais decisões, 37 no total, a reincidência foi utilizada como forma de compensação da confissão total do apenado, prevista no art. 65, III, d, do Código Penal.

No processo $n^{\circ}$ 0000710-69.2016.8.26.0548, o magistrado compensou reincidência e confissão, não agravando a pena do agente na segunda fase da dosimetria. Não obstante, o instituto foi utilizado como elemento para atestar a personalidade do réu e justificar a fixação do regime fechado para início de cumprimento da pena de 1(um) ano e 4 (quatro) meses de reclusão imposta. Senão vejamos:

Na primeira fase da dosimetria, atenta aos elementos norteadores do artigo 59 do Código Penal, fixo a pena-base em 02 (dois) anos de reclusão e 10 (dez) dias- 
-multa. Na segunda fase, a reincidência e a confissão se compensam. Na terceira fase, em razão do reconhecimento da tentativa, reduzo a pena em $1 / 3$, resultando, em definitivo, em 01 (um) ano e 04 (quatro) meses de reclusão, além de 06 (seis) dias-multa. O dia-multa valerá o mínimo legal. Não se encontram presentes os requisitos do artigo 44 do Código Penal, uma vez que o réu é reincidente (fls. 77) e ostenta vultosa folha de antecedentes, a qual inclusive envolve a prática de estelionato e outros furtos. Em que pese o quantum de pena fixado, $o$ regime inicial para seu cumprimento deverá ser o fechado ante a personalidade claramente inclinada à delinquência que possui o réu, que claramente leva como cotidiana a vida criminosa e no interior de prisões, como se pode inferir pela análise da documentação acostada aos autos. Insta, aliás, consignar seu desrespeito para com o Poder Judiciário, já que pouco se importa em voltar a delinquir mesmo após ser solto pelo cumprimento das penas que lhe são impostas. (grifo nosso).

No processo $n^{\circ}$ 0002936-88.2016.8.26.0114, o magistrado compensou a atenuante de menoridade relativa com a agravante da reincidência, o que resultou na mantença da quantidade da pena fixada na primeira fase da dosimetria.

B) Circunstâncias atenuantes e agravantes: menoridade relativa e reincidência (fls. 114/115), cujos efeitos devem se compensar, permanecendo a pena-base tal como fixada (...) E) Regime de cumprimento de pena: fechado, o único cabível para o caso, por expressa previsão legal, nos termos das Leis $\mathrm{n}^{\circ} \mathrm{s} 8.072 / 90 \mathrm{e}$ $11.464 / 07$, dispositivos que se encontram em plena vigência e eficácia, pois trata-se de crime hediondo, que atenta contra a saúde pública, com enormes consequências no meio social, sendo inclusive mola propulsora da prática de outros crimes contra o patrimônio e a incolumidade física, cabendo ao Juízo das Execuções analisar os requisitos subjetivos e objetivos do acusado para a concessão de eventuais benefícios (CP, art. 33, §§ $2^{\circ}$ e $3^{\circ}$ e CPP, art. 387, $\S 2^{\circ}$ ).

Nas 68 (sessenta e oito) decisões em que a reincidência implicou em um acréscimo na pena do condenado, o aumento de 1/6 (um sexto), prevaleceu, tal qual sugerido pela doutrina e jurisprudência. Não obstante, em 1 (uma) decisão a pena foi dobrada, em 2 (duas) foi acrescida em 1/2, em 09 (nove) decisões em 1/3, em 2 (duas) em 1/4, 4 (quatro) a acresceram em $1 / 5$ e 4 (quatro) em 1/8.

Vale salientar, nesse mister, que a legislação penal assevera uma ampla liberdade aos juízes na fase da dosimetria da pena, principalmente no que concerne à reprovação devida em razão da presença das agravantes, cujo quantum não está disciplinado na lei, mas é decidido pelos magistrados conforme as especificações de cada caso concreto e suas convicções acerca da gravidade da reincidência. De todo modo, nenhum magistrado justificou as razões pelas quais definiram o montante exasperado, somente fundamentaram a escolha pelo fato de o réu ter reincidido na prática delitiva. A fim de exemplificar essa questão, abaixo apresentam-se alguns trechos dos julgados encontrados:

Processo $n^{\circ}$ 0004851-75.2016.8.26.0114 - o acusado é reincidente (fls. 187/188). Acréscimo de $1 / 6$, resultando na pena de 03 anos e 06 meses de reclusão e 816 dias- 
-multa, unidade igual a 1/30 do salário mínimo vigente à época dos fatos.

Processo $n^{\circ}$ 0014595-31.2015.8.26.0114-Na segunda fase da dosagem, ante a agravante da reincidência específica (fls.131), aumento sua pena em 1/3 (um terço), ficando esta equivalente a $\mathrm{O} 3$ (três) anos, $\mathrm{O} 1$ (um) mês e 10 (dez) dias de reclusão e 14 (catorze) dias-multa.

Processo no 0000362-51.2016.8.26.0548 por ser reincidente em crime de roubo (fls. 52), aumento a pena para três anos de reclusão e ao pagamento de trinta dias multa, estes no mínimo legal.

Processo $n^{\circ}$ 0006415-89.2016.8.26.0114 sopesados os elementos norteadores do art. 59 do Código Penal, observo que o réu não possui maus antecedentes, o que justifica a fixação de sua pena-base no mínimo legal, ou seja, em cinco anos de reclusão e pagamento de 500 dias-multa. Em razão da reincidência (folha de antecedentes fls. 144/149), a pena-base deve ser aumentada, resultando sem eis anos e três meses de reclusão e pagamento de 625 dias-multa. Diante da reincidência, deixo de diminuir a pena, conforme previsto no artigo $33, \S 4^{\circ}$, da mesma lei. Esta pena torna-se definitiva, tendo em vista a inexistência de outras causas de aumento ou de diminuição.

Processo $n^{\circ}$ 0014011-27.2016.8.26.0114 tendo em vista a sua reincidência específica (certidões de fls. 149/150), AUMENTO ambas as penas de $1 / 6$ (um sexto), o que dá, como penal final, como pena corporal, 5 (cinco) anos e 10 (dez) meses de reclusão e, como pena pecuniária, 583 (quinhentos e oitenta e três) dias-multa. Descabida a compensação entre a atenuante da confissão e a agravante da reincidência uma vez que esta Magistrada entende que a reincidência é circunstância preponderante.

Processo $n^{\circ}$ 0037055-46.2014.8.26.0114 - além de ostentar antecedentes, o acusado é reincidente (fls. 13 do apenso próprio). Acréscimo de mais $1 / 6$, resultando na pena de 06 anos, 02 meses e 20 dias de reclusão e 15 dias-multa, unidade igual a 1/30 do salário mínimo vigente à época dos fatos

Processo $n^{\circ}$ 0000685-68.2014.8.26.0114 - na segunda fase da dosagem, ante a reincidência do réu (fls. 38), aumento sua pena na fração de 1/3 (um terço), o que resulta 07 (sete) anos, 09 (nove) meses e 10 (dez) dias de reclusão e 777 (setecentos e setenta e sete) dias-multa.

Processo $\mathrm{n}^{\circ}$ 0023724-65 2012. 8.26. 0114 - Conforme certidões de fls. 82 e 85 , o réu é duplamente reincidente, razão pela qual aumento a pena em $1 / 5$ para 06 (seis) anos de reclusão e 600 (seiscentos) dias multa. Não pode ser aplicada a atenuante da confissão, visto que esta não ocorreu em juízo. Inviável a aplicação de qualquer redutor por causa de reincidência e seja por ela, seja pela gravidade do crime, fixo o regime inicial fechado. Finalmente, ressalto que não há "bis in idem" na consideração da reincidência como agravante e como impeditivo de redução, já que não se provoca duplo aumento. Ainda que assim não fosse, o réu estava foragido no momento da prática do crime destes autos, o que demonstra que se dedicava a atividades criminosas, fato que de qualquer forma, impede a redução. 
No Processo nº 0000172-88.2016.8.26.0548, um dos casos em que a reincidência implicou no menor dos aumentos apurados - 1/8 - isso só ocorreu em razão da existência da atenuante da confissão.

Na segunda fase da dosimetria da pena, verifico a presença da circunstância atenuante prevista no artigo 65, III, d, do Código Penal (confissão espontânea), e da agravante prevista no artigo 61, I, do Código Penal (reincidência fls. 11/12 do apenso). Nos termos do artigo 67, do Código Penal, verifico que a circunstância agravante da reincidência prepondera sobre a atenuante da confissão espontânea, motivo pelo qual, a despeito de não realizar a compensação, agravo a pena anteriormente dosada em patamar menor, ou seja, $\mathbf{1 / 8}$, passando a 3(três) anos, 4 (quatro) meses e 15 (quinze) dias de reclusão e 11 (onze) dias-multa. (grifo nosso).

Ademais, quanto à pena final imposta ao condenado, vale mencionar que 5 (cinco) decisões tiveram as penas finais substituídas por restritivas de direitos, mesmo o réu sendo considerado reincidente. A respeito disso, o Código Penal no art. 44 veda expressamente a substituição da pena privativa de liberdade por restritiva de direito quando o réu for reincidente em crime doloso, mas é omisso quanto à reincidência em crime culposo. ${ }^{6}$ Nos casos elencados, devido à impossibilidade ao acesso de todas as etapas do processo criminal, não foi possível saber se os reincidentes cometeram os crimes anteriores na sua modalidade culposa ou dolosa, portanto a análise total ficou prejudicada. Caso as substituições de pena tenham sido concedidas aos reincidentes em crime ${ }^{6}$ Nos terços da Súmula 132, aprovada em março deste ano pelo TRF4 "na hipótese em que a condenação puder ser substituída por somente uma pena restritiva de direitos, a escolha entre as espécies previstas em lei deve recair, preferencialmente, sobre a de prestação de serviços à comunidade, porque melhor cumpre a finalidade de reeducação e ressocialização do agente". doloso, é um avanço a ser salientado, já que a lei penal proíbe esse ato.

Um dos casos em que a pena final foi substituída por restritiva de direitos foi no Processo $n^{\circ}$ 0001552-83.2016.8.26.0084, em que o réu se encontrava preso desde o flagrante, já tendo cumprido, quase que integralmente, $1 / 6$ da pena.

Ressalta-se, também, que em 27 (vinte e sete) decisões a punibilidade do agente foi extinta devido à prescrição retroativa da pretensão punitiva e houve somente 1 (um) caso de extinção da punibilidade pelo integral cumprimento da pena privativa de liberdade.

Quanto aos delitos cometidos, 57,4\% deles, aproximadamente, são classificados como crimes contra o patrimônio, como o furto (9\%), furto qualificado (13,5\%), roubo $(21,9 \%)$, receptação $(5,8 \%)$ e estelionato (5\%). Porém, conforme os dados coletados, o crime que teve maior incidência de reincidentes foi o tráfico de drogas, com $23 \%$ de recidivas. ${ }^{7}$

Em desconformidade com as críticas apresentadas acerca do instituto, nenhum magistrado se manifestou contrariamente à aplicação da reincidência e seus efeitos, diversamente, a maioria dos réus teve sua pena exasperada pelos juízes em razão da agravante. Outrossim, nenhum magistrado compreendeu-a capaz de atenuar a sanção penal.

Vale evidenciar que, mesmo nos casos em que a agravante não aumentou a pena do sentenciado, isto ocorreu em virtude da pre-

Oportuno salientar o posicionamento de Mellim Filho (2010, p. 253) quanto aos crimes patrimoniais, conforme o autor, "autores de crimes patrimoniais que chegam ao sistema judiciário penal e por ele são reconhecidos não passam de pequenos e miseráveis ladrões. Aqueles que acabam condenados por crimes como de apropriação indébita e estelionato são, igualmente, pequenos falsários, donas de casa que adquirem mercadorias de consumo doméstico e roupas com cheques sem fundos ou furtados, insignificantes empregados que se apropriam de pequenas quantias de que têm a posse para efetuar pagamentos etc. 
sença de atenuantes consideradas preponderantes, mormente da confissão total do apenado em relação ao cometimento delituoso ${ }^{8}$. Isto é, para que não houvesse a exasperação da pena fez-se necessário a compensação entre agravantes e atenuantes; porém, em tempo algum houve a ponderação acerca desse instituto ser demasiadamente penoso ao condenado quando aplicado.

Desse modo, a partir do estudo jurisprudencial, foi possível perceber que os magistrados de Campinas aplicam a legislação que determina o aumento da pena na segunda fase da dosimetria de maneira acrítica, já que nenhum deles opôs-se ao reconhecimento do instituto como agravante da pena.

\section{CONSIDERAÇÕES FINAIS}

Após examinar o instituto da reincidência, notou-se a existência de divergências doutrinárias quanto a sua legitimidade e aplicação. Embora o instituto seja reconhecido no Código Penal como uma medida tendente a agravar a situação daquele que já foi condenado por um crime anterior, seja por meio da exasperação da sua reprimenda, seja por meio da criação de obstáculos à progressão de pena, diversos críticos, partindo de conhecimentos do Direito Penal ou da Criminologia, asseveram que seu único propósito é o de permitir uma maior punição aos condenados, carecendo ser expurgada do ordenamento jurídico brasileiro, como demonstrado ao longo desse artigo.

Nesse sentido, evidenciou-se que a reincidência impacta negativamente sobre a situação penal e processual do condenado, violando alguns dos caros princípios que devem orientar o Direito Penal em um Es-

\footnotetext{
Insta salientar que a mencionada compensação, que já era comu mente realizada pelos magistrados, tornou-se objeto da Súmula 130 do TRF4 que estabelece que "a agravante baseada numa única reincidência e a atenuante da confissão espontânea, quando coexistirem compensam-se integralmente".
}

tado Democrático de Direito, tais como o ne bis in idem, a proporcionalidade, a dignidade da pessoa humana, entre outros.

Ademais, demonstrou-se também como a passagem de alguém pelo sistema penal, em razão da estigmatização social que provoca, colabora para que o indivíduo reincida na pratica ilícita, o que culmina na desviação secundária e na adoção de uma carreira criminosa.

Não obstante todas as suas consequências, buscou-se analisar mais detidamente uma delas, referente à sua previsão como circunstância agravante da pena, por meio da pesquisa jurisprudencial realizada.

Constatou-se, por meio da pesquisa de decisões realizada, que os magistrados atuantes nas Varas Criminais de Campinas agravam a pena dos réus em razão da reincidência, tal qual disposto no Código Penal, sem levar em conta nenhuma das reflexões lançadas pelos críticos do instituto. Em todos os casos encontrados, a reincidência foi considerada negativamente, como circunstância tendente a agravar a sanção penal do condenado, e só não aumentou o total de pena imposto quando compensada com uma atenuante.

Também foi possível identificar na pesquisa que os magistrados das Varas Criminais da cidade de Campinas, quando escolhem a fração de aumento de pena em razão da reincidência, apontam distintos montantes de exasperação sem, contudo, justificar a opção realizada.

Torna-se, portanto, indispensável a transformação do pensamento punitivo consolidado na legislação penal e aqui demonstrado pela agravação da pena em razão da reincidência, que ao invés de produzir efeitos 
positivos sobre a redução da criminalidade empurra cada vez mais o reincidente para dentro do cárcere, por mais tempo, e que faz com que a criminalidade seja a única opção condizente com o seu estigma.

\section{REFERÊNCIAS}

Almeida, D. S. (2013). Reincidência criminal: reflexões dogmáticas e criminológicas. Revista Síntese de direito penal e processual penal, 13 (78), 46-64.

Baratta, A. (2002). Criminologia Crítica e Crítica do Direito Penal: introdução à sociologia do direito penal. Rio de Janeiro: Editora Revan.

Barroso, D. V. S. (2009). Criminologia: do estado de polícia ao estado de direito. Florianópolis: Conceito.

Becker, H. S. (2008). Outsiders: estudos de sociologia do desvio. Rio de Janeiro: Jorge Zahar Ed.

Berla, G. V. (2010). Reincidência: uma perspectiva crítica de um instituto criminógeno. Revista Brasileira de Ciências Criminais, 18(82), 295-338.

Brasil. (1988). Constituição da República Federativa do Brasil.

Brasil (1940). Lei n².848 de 1940. Código Penal.

CARVALHO, S. (2001). Reincidência e antecedentes criminais: abordagem crítica desde o marco garantista. Revista de Estudos Criminais, 1, 109-119.

Franco, A. S (2010). Reincidência: um caso de não recepção pela Constituição Federal. Boletim IBCCRIM, 17(209), 2-3.

Freitas, R. B. A. P. (2009). Reincidência e repressão penal. Revista Brasileira de Ciências Criminais, 17(81), 92138.

García-Pablos de Molina, A. (1986). La normalidad del delito y el delincuente. Revista de la Facultad de Derecho de la Universidad Complutense, 11, 325-346.

Garland, D. (2014). A cultura do controle: crime e ordem social na sociedade contemporânea. Rio de Janeiro: Revan.

Goffman, E. (2008). Estigma: notas sobre a manipulação da identidade deteriorada. Rio de Janeiro: LTC.

Ibccrim. Comissão Amicus Curiae (2014). Inconstitucionalidade da consideração da reincidência como agravante. Revista Brasileira de Ciências Criminais, 22(108), 543-562.
Ifanger, F.C.A.; Poggetto, J. P. G. D. (2016). As finalidades ocultas do sistema penal. Revista Brasileira de Ciências Criminais, 24(124), 259-297.

Infopen (2017). Levantamento Nacional de Informações Penitenciárias. Responsável Departamento Penitenciário Nacional.

Instituto de Pesquisa Econômica Aplicada. (2015). Reincidência Criminal no Brasil. Coordenação A. Oliveira Júnior.

Lemert, E. M. (1951). Social Pathology: a systematic approach to the theory of sociopathic behavior. Nova Iorque: Toronto: Londres: McGraw-Hill.

Mellim Filho, O. (2010). Criminalização e seleção no sistema judiciário penal. São Paulo: IBCCRIM.

Sabadell, A. L. (2013). Manual de Sociologia jurídica: introdução a uma leitura externa do direito. São Paulo: Editora Revista dos Tribunais.

Santos, J. V. T. (2004). Violências e dilemas do controle social nas sociedades da "modernidade tardia". São Paulo em Perspectiva, 18(1), 3-12.

Santos, J. C. (2002). Política criminal: realidades e ilusões do discurso penal. Discursos Sediciosos: crime, direito e sociedade, 7(12), 53-57.

Schaffa, P. M. (2009). Sua pena não termina quando acaba. Boletim IBCCRIM, 16(195), 10

Tangerino, D. P. C. (2014). Culpabilidade. São Paulo: Saraiva.

Teixeira, A. (2014). O papel da reincidência criminal na aplicação da pena: reflexões a propósito do acórdão do RE 453.000 do STF. Revista Brasileira de Ciências Criminais, 22(108), 513-540.

Vargas, J. O.; Motta, F. H. R. (2009). Reincidência: uma agravante não recepcionada. Revista Magister de Direito Penal e Processual Penal, 6(32), 10-26.

Vilas Boas, G. A. (2003). Reincidência: agravante ou atenuante. Boletim IBCCRIM, 11(133), 14-15.

ZAFFARONI, E. R. (1996). Reincidencia. Revista de Ciencias Penales, 2, 119-127.

Zaffaroni, E. R. (2001). Em busca das penas perdidas: a perda da legitimidade do sistema penal. Rio de Janeiro: Revan.

Data de submissão: 04/02/2019

Data de aceite: 08/03/2020 